Pedagogía y Saberes No. 46

Universidad Pedagógica Nacional

Facultad de Educación. 2017, pp. 77-83

\title{
Derrida, herencia y educación ${ }^{*}$
}

Artículo de reflexión

Derrida, Heritage and Education

Derrida, herança e educação 


\title{
Resumen
}

El presente artículo derivado de una investigación doctoral en curso, extrae del legado filosófico de Derrida un concepto importante para pensar la educación: herencia. Concepto cuya filiación con lo educativo vale la pena hacer explícita en un tiempo para el que lo fundacional, diríamos con Sloterdijk (2015), pierde cada vez mayor relevancia en virtud de su marcado interés por la innovación permanente y la novedad. En ese orden de ideas, se plantea, mediante trazos más bien gruesos, dos cosas: primero, una breve semblanza respecto del pensamiento derridiano y su estela posestructuralista y, segundo, una lectura de la noción de herencia con base en la cual se controvierte aquella consigna de "borrón y cuenta nueva" que hace carrera en el seno de la escuela, dada la obsesión de muchos por querer, per se, transformarla, aun a expensas de su propio estatuto.

\section{Palabras clave}

Legado, maestro, escuela, tradición, filosofía, pedagogía.

\begin{abstract}
This paper derived from an ongoing PhD research project, takes from Derrida's philosophic legacy an important concept for thinking education: heritage. A concept whose relation to education deserves to be made explicit, in times in which the foundational power-we would say with Sloterdijk (2015)—increasingly loses importance due to its noticeable interest for permanent innovation and novelty. Therefore, this article introduces, in broad terms, two topics: firstly, an overview as to Derridean thought and its poststructuralist trail; secondly, an interpretation of the notion of heritage, which I refer to in order to contend the "starting with a clean slate" slogan that has been installed in the core of school, due to the obsession of many who pretend, per se, to transform it, even in spite of its own statute.
\end{abstract}

\section{Key words}

Legacy, teacher, school, tradition, philosophy, pedagogics.

\section{Resumo}

O presente artigo derivado de uma pesquisa doutoral em curso, retoma do legado filosófico de Derrida um conceito importante para pensar a educação: herança. Conceito cuja filiação ao educacional é importante explicitar hoje, um tempo no qual o fundacional, diríamos com Sloterdijk (2015), perde cada vez mais relevância em função de seu marcado interesse pela inovação permanente e a novidade. Nessa ordem de ideias, propõe-se, mediante linhas desenhadas de forma geral, duas coisas: primeiro, uma pequena descrição em relação com o pensamento derridiano e seu rastro pós-estruturalista e, segundo, uma leitura da noção de herança, com base na qual discuto aquela consigna de apagar e conta nova que fez carreira no seio da escola, a partir da obsessão de muitos por querer, per se, transformá-la, mesmo a costa de seu próprio estatuto.

\section{Palavras chave}

Legado, professor, escola, tradição, filosofia, pedagogia. 


\section{Derrida: pensador del rastro'}

- Qué combate Derrida? ¿Hacia qué blanco esgrime su discurso, blande sus argumentos? Claramente hacia la filosofía de Occidente, aquella tradición de pensamiento que basa su economía de sentido en presupuestos de cuño eminentemente racionalista, devotos de un discurso que promueve la búsqueda de la verdad, la existencia de un fundamento último, la avidez de identidad y unidad, el aborrecimiento hacia la diferencia, el culto al signo y al lenguaje como instancia de representación. En general, un discurso que fomenta la fe en el credo metafísico de Occidente, cuyo afán por explicar la realidad a la luz de un referente absoluto hace de este un discurso subordinado a la metafísica de la presencia, es decir, fiel a una metafísica entendida "como escritura teórica organizada en torno a un centro privilegiado: la presencia" (Derrida, 1989, p. 24) $)^{2}$.

A tal estado de cosas Derrida le llama: logofonocentrismo del discurso tradicional, y es en dirección a dicho frente que encauza su lucha. Una que se rebela contra la modernidad y su imperio racionalista. De este modo, el pensador levanta la bandera nietzscheana y ratifica sin rubores la muerte de todos los valores absolutos, la muerte de la idea misma de cimiente, de fundamento capaz de instituir una explicación del mundo a la cual plegarnos a través del reino de la representación, a la que ataca sin cuartel por cuanto dicha categoría da lugar a una conquista del ámbito mismo del conocimiento.

De allí la sintonía de Derrida con la crítica de Heidegger al problema de la representación, la cual lee -dadas las pretensiones idealistas atribuidas a elladetentadoras de la conciencia, como un imperativo equivalente a "tener la razón", es decir, a determinar lo que es; a establecer el sentido definitivo, a asegurar verdad. Desde tal punto de vista, representar connotaría siempre un principio pragmático de utilidad al tener que pensar. Así, se piensa en función de unos fines, con arreglo a unas reglas y en virtud de unos medios. Ello suscita el interés de Derrida por socavar las

1 De acuerdo con Dreher, Derrida asume el término rastro de cara a la imposibilidad de que un elemento se remita a sí mismo por cuanto es huella de otro. "No existe, en ninguna parte, más que diferencias y rastros de rastros" (Derrida, citado por Dreher, 2005, p. 33).

2 Esta perspectiva es tributaria por supuesto de un pensamiento representativo cuya idea de ser, de acuerdo con Peretti (1989), se ha interpretado como ser o razón de ser del ente, lo que termina por fortalecer consecuentemente la idea de presencia. "Este conjunto de consideraciones, aunado a la filosofía cartesiana, eleva la idea de representación al lugar de centro del pensamiento moderno, arraigando en Occidente una teoría del conocimiento profundamente idealista" (Valenzuela, 2014, p. 22). bases ontológicas que dan asidero a tal platonismo filosófico, de manera que sea posible.

[...] renunciar al pensamiento representativo, al Ser concebido como fundamento, al hombre como animal racional (convertido en sujeto en la época moderna), a las certezas del cogito, a la teoría del juicio y a la proposición sujeto-predicado (expresión por excelencia del pensamiento representativoexplicativo). (Peretti, 1989, p. 26).

Consideraciones de esta naturaleza, coincidentes con la pretensión de abolir toda aspiración a una regla absoluta en atención a la cual poder regirnos; de acabar con la demanda de una conciencia tributaria de sentido a través del cual cohesionar lo fragmentario de nuestra realidad encuentran eco en las plausibles -al menos para aquellos excomulgados por la tradición occidental como Nietzsche o Derrida- consignas defendidas por los giros posestructuralistas en razón de su abierto consentimiento hacia buena parte de las críticas hechas por Derrida al logofonocentrismo, concepto que atribuye al conjunto de elucubraciones que tornan al discurso occidental en una apuesta, que se profiere con el fin de arribar al sentido trascendental de nuestra existencia. Este anhelo se corresponde con un presupuesto vital para la tradición de la metafísica de la presencia, de acuerdo con el cual la raza humana ha de conducirse:

[...] hacia una moral universal, hacia la autorrealización intelectual y hacia el progreso sustentado en una razón científica, universal, educadora que, basada en métodos universales igualmente aplicables a todas las naciones y culturas y en una educación masiva, equipara los individuos con las habilidades, las actitudes y los atributos necesarios para tornarse ciudadanos útiles y buenos trabajadores. (Dreher, 2005, p. 35).

Y es justamente en razón de dicho menosprecio por la distinción, por la heterogeneidad, por lo Otro del que se parte siempre, que Derrida eleva toda una estrategia: la deconstrucción ${ }^{3}$, gracias a la cual da lugar, no a otro credo, no a otro discurso fundacional, no a otra metafísica espiritualista, sino a un movimiento que vive en el filo de la diferencia, en la escisión liminal de lo constituido y lo por-venir, en el "paso" que nunca se excede pero jamás recula, es decir, en el riesgo, en la renuncia a lo definitivo, a lo perentorio, al estrato último.

3 “... el término deconstrucción está tomado de la arquitectura. Significa deposición o descomposición de una estructura. En su definición derridiana, remite a un trabajo del pensamiento inconsciente ('eso se deconstruye') y que consiste en deshacer, sin destruirlo jamás, un sistema de pensamiento hegemónico o dominante" (Roudinesco, 2002, p. 9). 
En tal medida, a Derrida bien podríamos sumarlo a una ya larga lista de autores que auspiciaron, aunque de modo diferencial, diríamos, la dimisión de la tradición filosófica occidental como centro del sistema de pensamiento actual: desde Nietzsche y Heidegger, hasta Rorty y Goodman, pasando por Vattimo, Ortega, Welsch, Bohr, Foucault y Wittgenstein, entre otros muchos, cuyas maneras de pensar claramente hicieron tambalear en sus bases la metafísica de la presencia, tan severamente atacada por Derrida.

Dicha constelación de autores, ciertamente, conmocionó a lo largo del siglo xx las seguridades sobre las que se soportaba nuestra episteme moderna, a partir de lo que algunos han dado en llamar el triple giro epistémico (Bermejo, 2008). Ahora, la singularidad de dichos giros en relación con la transformación a la que se ha sometido el estatuto del conocimiento moderno, a través del posestructuralismo, nos remite sin lugar a dudas a Derrida en la medida en que sus reflexiones convergen profundamente con las tesis respaldadas tanto por el giro lingüístico como por el pragmático y el estético. Detengámonos brevemente en lo que concerniría a la gramatología derridiana de los giros señalados.

\section{Derrida y los giros lingüístico, pragmático y estético}

Uno de los postulados que daría lugar a la emergencia del giro lingüístico, en estrecha relación con el legado derridiano, tiene que ver con la noción de lenguaje a la que se adscribirían sus partidarios, y es esta una acepción que aleja al lenguaje del ideario representacionista que lo conminó a ser instrumento de mediación entre la conciencia y las cosas; como si el lenguaje fuese informativo de hechos y no, como lo entiende Derrida, constitutivo de realidad. Así, tanto para el giro lingüístico como para Derrida,

\begin{abstract}
... las proposiciones no son [como ya se ha señalado] ni expresión de una conciencia pura que descubre las estructuras a priori de las cosas -mito de la conciencia y de la lógica (Wittgenstein, Davidson, Rorty)- ni representación pura de las estructuras objetivas de una naturaleza independiente -mito de la objetividad de la ciencia física de lo dado (Sellars, Quine). (Bermejo, 2008, p. 52).
\end{abstract}

De esta manera, sobre los hombros del lenguaje deja de pesar la figura de la presencia a la que lo había condenado Occidente, a través del paradigma representacionista, del paradigma del signo.

Ahora bien, en relación con el giro pragmático, cuya tesis esencial hace nexo con la naturaleza singular y contextual del hecho lingüístico, cabe rescatar el prota- gonismo que allí ocupa la idea de un significado nunca ajeno al sentido que el uso de la palabra o el "gesto" exigen en un contexto determinado. De modo que, de acuerdo con lo anterior, "ninguna proposición es ajena a interés, contexto, historia, ideología, teleología, etc." (Bermejo, 2008, p. 53), por lo tanto, no habría en consecuencia sentido capaz de preceder al uso de la palabra escrita -pues este solo emerge en el dar a leer del aquí y el ahora-pero tampoco de sucederla, pues, para Derrida, y aquí quizá habría un posible punto de inflexión, es la ausencia como huella la que habita a la palabra inscrita, de lo contrario permaneceríamos atados a la metafísica del signo-señal.

En cuanto al giro estético, cabría señalar la preeminencia que este le otorga a un principio caro también para Derrida: el de la ausencia de un fundamento último y definitivo, cuyo corolario no podría ser otro que el del carácter ficcional de la presencia, a la que este giro renuncia en la medida en que "recupera la centralidad de la creatividad en toda actividad humana, la metaforización como estrategia cognitiva básica y la pérdida de densidad ontológica de la realidad (Nietzsche, Ortega, Vattimo)" (Bermejo, 2008, p. 53).

Así pues, el legado de Derrida, aunado al de Nietzsche, estribaría en combatir sin cuartel los valores absolutos que entronizan la razón y el signo en detrimento de otros registros sustanciales mediante los cuales reivindicar dimensiones condenadas al olvido por la modernidad, como la imaginación y el lenguaje en sus diversas manifestaciones.

Ahora, lo dicho hasta aquí bien podría sugerir la imposibilidad -dado el carácter disidente del discurso derridiano frente a la noción misma de fundamento, o principio primero- de hablar sobre la herencia en una clave que no fuese otra que la de su disolución, por aquello justamente de considerar la inexistencia de un discurso que "pueda ser considerado neutro o que pueda representar una síntesis, el centro, una supuesta unidad o universalidad" (Dreher, 2005, p. 38). Sin embargo, Derrida no es ingenuo y sabe bien que su filosofía no puede reducirse a una vana aspiración, es decir, a la pretensión de trascender el umbral de la metafísica que tanto critica. La idea de un ir más allá lleva ínsita de hecho lo que Derrida combate: la hybris ${ }^{4}$.

No hay una transgresión si por esto entendemos la instalación pura y simple en un más allá de la metafísica, en un punto que sería también, no olvidemos, y sobre todo, un punto de lenguaje o de escritura. Caramba, aun en las agresiones y transgresiones

4 Como afirma Castro Gómez "De hecho, la hybris es el gran pecado de Occidente: pretender hacerse un punto de vista sobre todos los demás puntos de vista, pero sin que de ese punto de vista pueda tenerse un punto de vista". 
utilizamos un código al cual la metafísica está irreductiblemente ligada, de manera tal que todo gesto transgresor vuelve a encerrarnos dentro de la metafísica -precisamente porque ella nos ha servido de punto de apoyo [...] No nos instalamos jamás en una transgresión, no habitamos jamás otro lugar. (Derrida citado por Dreher, 2005, p. 39).

El ansia fútil de eludir lo que, al cabo, nos concede la posibilidad de idear la renuncia, de ingeniar la salida es algo que Derrida no solo advierte perfectamente, sino que además, ventila al hablar de la deconstrucción, vía a través de la cual, precisamente, elogia lo establecido, valora lo heredado, pues el gesto deconstructivo estriba en resistirse sí a la tiranía del Uno, del logos, de la metafísica (occidental) (Derrida y Roudinesco, 2002) pero en su propio terreno, al que deshace sin horadarlo nunca. En esto consiste la deconstrucción, en aprender a amar aquello con lo que queremos "agarrárnoslas".

\section{Herencia y responsabilidad}

¿Cómo elogiar lo legado por una educación a la que hoy, febrilmente, se tilda de tradicionalista, memorística, autoritaria y academicista? ¿Cómo aguarles la fiesta de la innovación a muchos pidiéndoles que "amen" la tradición? ¿Cómo instarlos a "reafirmar" aquello que esperan que desaparezca a toda costa? Exhortándolos quizá a saber ser herederos, es decir, a saber ser responsables, tanto de cuanto viene como de cuanto dejan. Y muy especialmente de aquello cuanto dejan, que parece ya olvidado. En efecto, la época por la que atravesamos en el presente no parece distinguirse propiamente por ser respetuosa de su pasado. De hecho, como señala Sloterdijk (2015):

En todos los contextos civilizatorios recientes la ventaja irrecuperable de lo actual sobre lo legítimo -de lo dado casualmente sobre lo fundamentable, del de facto sobre el de iure- se manifiesta como exceso creciente de una facticidad salvaje que hace acto de presencia de forma inesperada e incontrolada. La proclama de los bienpensantes [sic] de que también y precisamente hoy el futuro necesita origen, da efectivamente testimonio de la conciencia problemática creciente de la fragilización de continuidades civilizadoras. Hoy ya no representa más que un grito indefenso dentro de la deriva global, que demuestra justamente lo contrario: quien siente contemporáneamente sabe en toda terminación nerviosa lo mucho que se ha liberado lo futuro de la carga del origen. (p. 62).

Grito del que poco se hace eco hoy en las escuelas, deseosas por diversos motivos de cambiar para mejorar, consigna a la cual le causa ruido precisamente la idea de la herencia y sus supuestas secuelas conservaduristas que obturarían el cometido de la transformación a la que, casi que por ley, ha de aspirar todo claustro educativo. La figura del heredero, en consecuencia, cede o se desplaza ante el ímpetu del innovador, quien mira solo hacia delante en busca de lo abierto. El origen yace atrás y por tanto fuera del rango de visión de aquel para el que la herencia no irradia sino solemnidad, cuando no indiferencia o, incluso, repudio. Hoy el proscrito es el maestro al que se le pide que deje de serlo, pues su idoneidad ahora se cifra en la habilidad que él tenga, no de enseñar sino de no impedir aprender, de no hacer estorbo. De allí que muchos maestros hoy por hoy tengan que esforzarse por no hacer nada en clase $^{5}$ so pena de ser abucheados por los estudiantes, al no permitirles aprender mediante asignación de exposiciones o trabajos en grupo.

Es tal condición contemporánea de lo educativo la que me remite aquí a la pregunta por la herencia, por el legado. ¿Se trata ahora de saludar a la bandera? Por supuesto que no. Y menos patrocinados por un filósofo como Derrida cuya disidencia, ya expuesta, no comulga con dogmatismos e impele, por el contrario, a no aceptarlo todo, pero también y al mismo tiempo, a no barrer con todo, pues, la deconstrucción no es sinónimo de disolución, es, más bien, un acto de acogida cuyo motor radica en vérselas sincera y amorosamente con aquello que encara y cuestiona.

Es por ello que al hablar de la herencia en educación no tendría objeto hacerlo desde un conservadurismo a ultranza -el otro extremo- para el que solo fuese importante plegarse pasivamente a la voluntad de la tradición. Derrida, por el contrario, ofrece una mirada respecto de la herencia que, a decir verdad, no se sintoniza con esa incondicional entrega a lo heredado. De hecho, la lealtad a la que la herencia obliga supone en Derrida un margen de infidelidad, que en todo caso no es deslealtad, pues de lo que se trata es de asumir libremente lo que nos precede, no de digerirlo de modo irrestricto, lo cual hace del hecho de ser legatario una verdadera responsabilidad y no una mera contingencia:

Al explicarme de manera insistente sobre ese concepto o figura del legatario, llegué a pensar que, lejos de una comodidad garantizada que se asocia un poco rápido a dicha palabra, el heredero siempre

5 No hablamos aquí, como se habrá advertido, del maestro que, en cambio, a fuerza de enseñar lo que no se sabe, exhorta al otro a aprender: "Jacotot no decía que un maestro no necesitaba saber nada, mucho menos hubiera afirmado que un maestro renunciara a enseñar. Sostenía, en cambio, que es en la emancipación del otro, allí donde todo otro es llevado/obligado a usar su propia inteligencia por alguien que confía en ella, donde algo puede ser aprendido" (Frigeiro, 2005, p. 136). 
debía responder a una suerte de doble exhortación, a una asignación contradictoria: primero hay que saber y saber reafirmar lo que viene "antes de nosotros", y que por tanto recibimos incluso antes de elegirlo, y comportarnos al respecto como sujetos libres. (Roudinesco y Derrida, 2002, p. 12).

Actualmente, ser renuente a la tradición por simple consigna o moda es algo muy usual en la educación. De allí derivan las habituales diatribas contra, sencillamente, lo anterior: autores, teorías, discursos, obras, en fin. La aversión por lo clásico se ha tornado "clásica" y ha impedido heredar y, en consecuencia, decidir. La costumbre de comenzar siempre de nuevo sin sopesar lo precedente ha sido lo único que no ha cambiado en mucho tiempo, y de ello apenas si somos conscientes. Las renovaciones a las que sometemos programas, cursos, currículos, metodologías e instituciones no obedecen a otra cosa que a la demanda básica de innovación por simple novedad. Aún más, si se tratase de sumar consecuencias a las ya enlistadas ${ }^{6}$ por Sloterdijk (2015) al hablar de la imposibilidad de controlar hoy por hoy los procesos modernos de vida y su entropía, justamente por tal apertura a la innovación, podríamos incluir la siguiente: tras la incursión en la era de la autoevaluación se invertirán más horas en los procesos de acreditación de las que jamás puedan dedicarse a enseñar e investigar, objetos paradójicamente de la misma evaluación.

En tal orden de ideas, pensar en la herencia y su reafirmación no tiene cabida en un presente educativo para el que el legado, de entrada, obnubila el por-venir y, por tanto, se justifica su aniquilación. Ostracismo al que ya han sido condenados muchos autores solo por no ser recientes o haber pasado supuestamente de moda, lo que, de paso, viene revelando serías repercusiones en lo que respecta al asunto mismo del saber ${ }^{7}$ en la educación. Ahora, no se trata, reitero, de reivindicar con lo anterior conservadurismos ortodoxos. Por el contrario, y de allí la recurrencia a Derrida, se trata de advertir cuán responsables estamos siendo en relación con un mañana al que le

6 En general proposiciones que, de acuerdo con Sloterdijk, "son enunciados dinámico-civilizatorios de un grado medio de abstracción, que se orientan por el principio de la apertura de consecuencias de la innovación, ya se trate de innovaciones técnicas, innovaciones jurídicas, innovaciones de comportamiento o innovaciones de objetivos" (2015, p. 65).

7 Hoy por hoy le rendimos pleitesía más al rito de la consulta, la pesquisa o el rastreo que al hallazgo mismo, pues, para la época lo esencial es del orden del estar sabiendo, no de lo "sabido", objeto este que se desvanece, llevándose consigo cualquier intentona de acotamiento a medida que el ideal de saber se enciende, "[...] cavilar [que] nunca encuentra un término [...] [y] se traslada cada vez, situándose más y más lejos” (Freud, 2003, p. 74). hemos negado un origen, rehusándonos a elegir de lo acontecido aquello que tengamos a bien como sujetos libres, pues solo decidiendo nos hacemos, de acuerdo con Derrida, legatarios.

Heredar, por tanto, desde esta perspectiva sería irreductible a replicar lo legado, a permanecer fiel a lo entregado. Heredar implica reafirmación y esta, en Derrida, equivale, no solo a aceptar la herencia sino, además, a "reactivarla de otro modo" (Derrida y Roudinesco, 2002, p. 12). Así las cosas, re-afirmar no es llanamente afirmar de nuevo, es también interrumpir de ser el caso, lo que implica elección, decisión. Afirma Derrida: “... un heredero no es solamente alguien que recibe, es alguien que escoge, y que se pone a prueba decidiendo" (p. 16).

Elegir, por consiguiente, es un acto de responsabilidad tanto para con lo que nos precede, por cuanto se nos lega, como para con lo por-venir, como acontecimiento imprevisible al que podemos dar lugar. Al enseñar, querámoslo o no, decidimos en relación con aquella herencia que nos antecede. Sin embargo, muchas veces elegimos desdeñarla, no a partir del escrutinio al que cabría someter lo heredado, sino en función de la consigna: "borrón y cuenta nueva" a la que mueve el afán de novedad en las escuelas. Y, de paso, abocamos a la irresponsabilidad simultáneamente cuando, en clase, no hacemos evidente el criterio de nuestras elecciones o, aún más, de nuestras supresiones. Porque el heredero -todo maestro lo es- se hace tal no solo al recibir sino además, y principalmente, al pronunciarse respecto de lo recibido.

Por lo tanto, se parte de “... esa contradicción formal y aparente entre la pasividad de la recepción y la decisión de decir 'sí', luego seleccionar, filtrar, interpretar, por consiguiente transformar, no dejar intacto, indemne, no dejar a salvo ni siquiera eso que se dice respetar ante todo" (Derrida y Roudinesco, 2002, p. 12). Un no dejar a salvo, aclarémoslo, que excluye la aniquilación e invita más bien a la re-afirmación de lo que se hereda; reafirmación que demanda serle infiel a lo heredado precisamente para honrarlo, "de aquí proviene la idea de que la mejor manera de ser fiel a una herencia es serle infiel, es decir, no recibirla literalmente, como una totalidad, sino más bien pescarla en falta, captar su momento dogmático" (p. 10).

Pero esa captación implica aceptación, no rehusar de tajo a lo heredado por mero capricho, por moda o porque es lo políticamente correcto. La deconstrucción misma, que muchos tildan de arrasadora, prohíbe precisamente herir o aniquilar. "La experiencia de una deconstrucción nunca ocurre sin [...] amor. Comienza por homenajear aquello, aquellos con los que se las agarra" (p.13). 
Como verán, se habla aquí de la herencia no con el fin de promover un culto al recuerdo en la escuela y escribir una oda al pasado, señalando que todo tiempo pretérito fue mejor. Lo que está en juego tiene relación con la forma en que, como maestros $y$, por tanto, como arcontes ${ }^{8}$, nos agarramos con lo que se nos lega; respondemos al llamado que se nos hace de recibir y reaccionar ante lo concedido para mantenerlo en vida, sin que ello implique replicarlo a perpetuidad:

Si la herencia nos asigna tareas contradictorias (recibir y sin embargo escoger, acoger lo que viene antes que nosotros y sin embargo reinterpretarlo, etc.), es porque da fe de nuestra finitud. Únicamente un ser finito hereda, y su finitud lo obliga. Lo obliga a recibir lo que es más grande y más viejo y más poderoso y más duradero que él. Pero la misma finitud obliga a escoger, a preferir, a sacrificar, a excluir, a dejar caer. Justamente para responder al llamado que lo precedió, para responderle y para responder de él, tanto en su nombre como en el del otro. El concepto de responsabilidad no tiene el menor sentido fuera de una experiencia de la herencia. (Derrida y Roudinesco, 2002, p. 13).

En tiempos de bastardía, donde lo heredable es sinónimo de desechable para muchos, la educación, pues, nos increpa e insta como maestros a hacernos cargo de repartir la herencia, aquel regalo concedido por quienes nos precedieron, y del que precisamos saber extraer, saber conservar, saber renunciar, saber escoger y, aún más importante, enseñar a hacerlo. El trabajo del maestro, en consecuencia, no solo consiste en "distribuir la herencia, [...] designando al colectivo como heredero (designación que se propone impedir que nadie quede marginado de la socialización y de la distribución)" (Frigeiro, 2005, p. 135); su labor también le impone, nada más y nada menos que habilitar

[...] a cada heredero a decidir sobre su posicionamiento frente a lo heredado (manera de significar que nadie está obligado a recibir la herencia sin recibir al mismo tiempo la libertad para decidir sobre ella, aceptarla, rechazarla, continuarla, modificarla, sobre todo inventarla). (p. 135).

Solo en tal medida, podremos arrogarnos el título de legatarios, es decir, de maestros.

8 "Arconte es la palabra que designaba al funcionario en quien se confiaba la custodia del archivo, custodia que no debe confundirse con una mala interpretación de lo policial, sino que debe entenderse como autoridad y confianza acordada para que algo esté cuidado" (Frigeiro, 2005, p. 134).

\section{Referencias}

Bermejo, D. (2008). Estetización epistemológica. En: D. Bermejo (ed.). En las fronteras de la ciencia. Barcelona: Anthropos, pp. 51-82.

Castro-Gómez, S. (s. f.). Decolonizar la universidad. La hybris del punto cero y el diálogo de saberes. Recuperado de http://www.uv.mx/veracruz/cosustentaver/ files/.../14-castro-descolonizar-la-universidad.

Derrida, J. (1989). Fuerza y significación. En: La escritura y la diferencia. Barcelona: Anthropos, pp. 9-46.

Derrida, J. y Roudinesco, E. (2002). Y mañana, qué... México: Fondo de Cultura Económica.

Dreher Heuser, E. (2005). En el rastro de la filosofía de la diferencia. En: C. Skliar y G. Frigerio (eds.). Huellas de Derrida. Ensayos pedagógicos no solicitados. Buenos Aires: Editorial del Estante, pp. 33-50.

Freud, S. (1910). Un recuerdo infantil de Leonardo da Vinci. En: Obras completas (vol. XI). Buenos Aires: Amorrortu.

Frigerio, G. (2005). Acerca de lo inenseñable. En: C. Skliar y G. Frigerio (eds.). Huellas de Derrida. Ensayos pedagógicos no solicitados. Buenos Aires: Editorial del Estante, pp. 125-149.

Peretti, C. de (1989). Jacques Derrida. Texto y deconstrucción. Barcelona: Anthropos.

Sloterdijk, P. (2015). Los hijos terribles de la Edad Moderna. Barcelona: Siruela. 